Revista Portuguesa de História

t. XXXVI (2002-2003)

pp. $135-149$ (vol. 2)

\title{
Empresas e Empresários: \\ Que Lugar na História Económica e Social?'
}

JOSÉ AMADO MENDES

Faculdade de Letras da Universidaded de Coimbra

Centro Interdisciplinar do Século XX - CEIS 20

\section{Introdução}

A história económica e social, ao longo de mais de um século de existência, tem registado um desenvolvimento considerável. Todavia, como geralmente sucede com outras disciplinas novas que procuram afirmar-se e demarcar um terreno de pesquisa com identidade, objecto e métodos próprios, também neste caso têm surgido vicissitudes, sobre as quais convirá reflectir.

Por sua vez, como qualquer outra especialidade historiográfica, a história económica e social tem relações estreitas com outras áreas ou subáreas de inveshgação, das quais recebe colaboração e às quais fornece, também, apoio e contributos. Entre as novas áreas de pesquisa que se afiguram mais promissoras conta-se, precisamente, a da história das organizações. Esta abrange, obviamente,

' $O$ texto que ora se publica, revisto e com o título ligeiramente alterado, também serviu de base a uma comunicação por mim apresentada (em 02.04.2003) ao Colóquio «Portugal-Brasil. Uma visão interdisciplinar do Século XX», organizado em Coimbra (na Faculdade de Economia), no âmbito do Centro Interdisciplinar do Século XX - CEIS 20. Foi igualmente publicado nas respectivas actas. 
não só as empresas - seu principal filão -, mas também vários outros tipos de organizações, incluindo as não lucrativas, de solidariedade social e de cultura. Recordam-se apenas alguns exemplos: corporações de bombeiros, hospitais, escolas, associações de defesa e salvaguarda do património cultural e organismos desportivos.

Para que os progressos na investigação histórica, nos vários domínios, possam ser mais adequadamente aproveitados e rendibilizados, torna-se necessário entrosar os resultados das diversas pesquisas e estar-se atento ao que se vai averiguando, nas múltiplas vertentes da produção historiográfica. Assim, paralelamente à crescente especialização que tem vindo a verificar-se, há que elaborar estudos de síntese, nos quais se conjugam os conhecimentos oriundos de diversos ramos especializados. Contudo, dado o avanço constante das áreas de especialização, nem sempre se torna fácil obter um nível razoável de actualização, pelo que, em muitos casos, se continuam a ignorar os resultados alcançados noutros níveis de especialização. Outras vezes, porém, efectua-se uma nova abordagem das questões, já com a incorporação de descobertas e perspectivas mais recentes (a obra coordenada por Thomas K. McCraw, adiante referenciada, constitui um bom exemplo do que acaba de afirmar-se). Estas muito contribuem para lançar uma outra luz sobre os assuntos anteriormente mal esclarecidos e compreendidos.

\section{História Económica e Social: um Percurso Sinuoso}

As últimas duas centúrias têm sido caracterizadas pela criação e pelo desenvolvimento de um conjunto significativo de novas ciências, tanto da natureza e experimentais como humanas e sociais.

Abandonado, sobretudo a partir do século XVIII, o paradigma do enciclopeismo aristotélico - por ter deixado de dar resposta cabal às novas questões e exigências entretanto emergentes -, tornou-se necessário enveredar por novos paradigmas, mais susceptíveis de ajudar a solucionar problemas entretanto detectados. Assim, a ciência então considerada "normal", usando a expressão de T. S. Kuhn², foi sendo paulatinamente substituída pelas novas ciências, ou seja, por novas teorias, metodologias e perspectivas de análise.

No que à história diz respeito, após o contributo de Adam Smith, em finais de Setecentos, ao lançar as bases da economia política e da própria economia, outras especialidades vieram posteriormente a ser desenvolvidas, tais como,

¿Thomas S. khun. La structure des révolutions scientifiques (trad. do inglês), Paris. Flammarion, 1972, p. 25. 
por exemplo, as seguintes: história diplomática e história militar; história da arte, história da cultura e história da religião, história regional e história local; história agrária, história industrial; história do comércio e dos transportes.

Todavia, antes que estas e outras especialidades das ciências históricas tivessem adquirido certa autonomia, começaram por ser apenas tópicos focados em histórias gerais, aos quais se dedicavam algumas páginas ou, quando muito, um ou outro capítulo. Assim sucedeu, também, com a história económica. Esta só aparece, como disciplina autónoma, nos Estados Unidos da América, em finais do século XIX ${ }^{3}$. Nas primeiras décadas do século passado, começou também a ser investigada e leccionada em alguns países europeus, por vezes ligada à história social.

Como já foi salientado, por 1907, a história económica já parecia ter adquirido, em França, uma certa legitimidade científica, ao ter sido criada em Paris, no "Collège de France", uma cadeira da especialidade 4 .

O seu desenvolvimento prosseguiu nas décadas imediatas, tendo encontrado terreno propício, resultante da contestação que já então se fazia sentir à história tradicional. Com efeito, a história económica e social permitia dar uma resposta satisfatória aos que criticavam (ainda que, por vezes, só implicitamente) o predomínio do político, do militar, do factual e da cronologia.

Foi neste contexto que os ideais da nova história se propagaram, para o que muito contribuíram a revista Annales (publicada em França, a partir de 1929) e o respectivo grupo de investigadores. Passou a privilegiar-se o estudo das estruturas e dos fenómenos de massa, com o recurso à documentação seriada (surgindo, assim, a "história seriar"), com particular relevo para a história dos preços e dos salários e, um pouco mais tarde, para a demografia histórica. Como notou Vitorino Magalhães Godinho, «nascia uma nova história económica, fundamentalmente estatística» ${ }^{5}$.

Acrescente-se, ainda, que o "imperialismo histórico" que, a partir dos anos 1950, substituiu o "imperialismo sociológico"', também contribuiu para reforçar o prestígio da história económica e social.

${ }^{3}$ A primeira cadeira de história económica, no mundo anglo-saxónico, foi criada na Universidade de Harvard, em 1893, e teve como primeiro docente o inglês W. J. Ashley (F. Mendels, «Histoire économique», Andrè Burguière [dir], Dictionnaire des Sciences Historiques, Paris, PUF, 1986, p. 217).

' Hartmut Atsma e André Burguière (coords.), Marc Bloch aujourd'hui. Histoire comparée \& sciences sociales, Paris, Ed. da École des Hautes Études en Sciences Sociales, 1990, p. 97.

Vitorino Magalhães Godinho, Introdução à história económica. Lisboa, Livros Horizonte, s. d., p. 52.

' Bouda Etemad et al. (eds.), Pour une histoire économique et sociale internationale. Mélanges offerts à Paul Bairoch, Genève, Ed. Passé Présent, 1995, p. 88. 
Por seu lado, no mundo anglo-saxónico, por meados do século XX, a história económica vai dar origem a uma nova modalidade, denominada new economic history. Dada a sua natureza e características, a ela aderiram mais facilmente economistas do que historiadores, de formação tradicional. Efectivamente, o recurso frequente à teoria económica e à estatística, a utilização de modelos, o uso do "contrafactual" e uma determinada obsessão pelo quantitativo (com algum menosprezo pela análise qualitativa), pelo que também é conhecida pelo nome de cliometria, tornam-na algo rebarbativa e sofisticada.

No terceiro quartel de Novecentos a história económica e social continua a desenvolver-se, com a leccionação de disciplinas em áreas especializadas: história da população e história do comércio, história da agricultura e história da indústria, história da moeda e da banca, história dos transportes, história dos negócios e história social. Das 35 revistas especializadas em história económica e social, criadas nos diversos países, entre 1871 e 1985, 26 (74\%) surgiram nos últimos 33 anos (1952-1985)?

Todavia, simultaneamente foram-se consolidando outras áreas historiográficas, com o estudo de novos temas que, a pouco e pouco, se tornaram mais apelativos: mentalidades e costumes; moda, vestuário e alimentação; vida privada e quotidiano; estudo das mulheres e de grupos sociais específicos; inovações, tecnologia e sua difusão.

Algum hermetismo dos textos de história económica e social - por vezes repletos de quadros e gráficos, com grande profusão de dados quantitativos -, a secundarização do discurso narrativo, da biografia e da prosopografia (segundo alguns autores, o homem, como tal, como que foi esquecido) contribuíram para provocar um certo afastamento do grande público da história económica e social e para que esta tivesse ficado confinada quase só aos especialistas.

Consequentemente, pelos finais dos anos 1980, já se detectava uma crise na história económica, em vários países, embora a sua origem remontasse à década anterior. Aludindo ao assunto, sublinha Carlo M. Cipolla: «No Ocidente, por meados dos anos 1970, os consumidores da história económica, isto é, os estudantes universitários e o público leitor começaram a perder o interesse pelos fenómenos puramente económicos. Assim, a obra histórica começou a atrair menos atenção, uma vez que o interesse se tinha deslocado - especialmente entre a juventude - para tópicos obviamente mais "relevantes", tais como os assuntos ecológicos e sociais» ${ }^{8}$.

Carlo M. Cipolla, Between History and Economics. An introduction to Economic History (trad. do italiano), Grã-Bretanha, Basil Blackwell, 1991, p. 4-5.

${ }^{8}$ C. M. Cipolla, idem. p. 74 (nesta, como noutras citações a partir de língua estrangeira, a tradução é da minha responsabilidade). 
Antes de concluir a presente alínea, vejamos a pertinência e a definição da expressão "história económica". Esta, como outras disciplinas historiográficas, surgiu como abstracção e por motivos pragmáticos, nomeadamente a necessidade de aprofundar a investigação de certos assuntos. Deve-se também a Cipolla a seguinte advertência:

«Tal como homo faber ou homo philosophicus, homo oeconomicus é uma abstracção. A realidade compreende pessoas com toda a sua complexidade biológica, psicológica e social. Similarmente, a sociedade não funciona em comportamentos estanques: ela opera mais como um todo vasto e complexo, articulado a níveis diferentes, emaranhados e interdependentes. Como na vida real, não há tal coisa como história económica, assim como não há história política, história social, história cultural ou história da tecnologia. Ao invés, o que há é exactamente história, isto é, a vida na sua infinita e complexa variedade, uma magma em contínuo fluxo, poderoso embora frágil»?.

Não obstante as observações acabadas de citar, o mesmo autor propõe a seguinte definição: «A disciplina conhecida como história económica [...] é a história dos factos e eventos económicos, na sua relação com os indivíduos, as empresas ou as comunidades $»^{10}$. Na impossibilidade de focar, nas presentes circunstâncias, todos os factores referidos e de acordo com o título em epígrafe, consideremos, de forma um pouco mais desenvolvida, a questão das empresas.

\section{História de Empresas: um Filão a Explorar}

"História empresarial" e "história de empresas" são expressões usadas, por vezes, na mesma acepção. Embora no presente texto também seja adoptado esse critério, alguns autores distinguem-nas. Assim, segundo Carlos Marichal, «a história empresarial - no sentido schumpeteriano - centra a sua atenção na análise histórica do desempenho e efeito de certos empresários inovadores individuais ou de determinados grupos de empresários de vanguarda». Por sua vez, «a história de empresas ou business history presta uma atenção especial à análise das mudanças na organização económica das companhias ou corporações, mudanças que são parte e reflexo das transformações económicas e sociais no seu conjunto»".

C. M. Cipolla, idem, p. 4.

10 C. M. Cipolla, idem, p. 3.

"Carlos Marichal e Mario Cerutti (comps.), Historia de las grandes empresas en México, 1850-1930. México, Universidad Autónoma de Nuevo Léon/Fondo de Cultura Económica, 1997, p. 10. 
Entre as diversas perspectivas utilizadas neste tipo de estudos, destacam-se as duas seguintes: a) uma de carácter macro, segundo a qual se estudam as estratégias empresariais e de gestão, a estrutura e a escala das organizações e a relação destas com o modelo de desenvolvimento económico. Como exemplos, podem apontar-se os trabalhos incontornáveis de Alfred Chandler, nos quais são analisados diversos tipos de capitalismo: de gestão (Estados Unidos da América), pessoal (Inglaterra) e cooperativo (Alemanha) ${ }^{12}$; b) outra de tipo micro, privilegiando o estudo específico de determinada empresa, que pode ser considerado uma espécie de biografia.

Foi este tipo de história que surgiu em primeiro lugar. Ainda no século XIX, de forma pontual, mas sobretudo na primeira metade do século passado foram elaboradas algumas histórias de empresas. Não deixa de ser interessante recordar que já o "nosso" José Acúrsio das Neves (1766-1834), pelos anos 1820, sublinhava as potencialidades da história das organizações. Cerca de um século mais tarde, a empresa Vista Alegre, ao comemorar o seu primeiro centenário (1924), colocou no centro das comemorações precisamente a publicação da respectiva história, que constitui um marco importante neste género de iniciativas.

A despeito de algumas chamadas de atenção, nos primeiros números dos Annales (década de 1930), para a importância do estudo das empresas e dos empresários - "cruzada" em que também, pela mesma altura, se empenhava Joseph Schumpeter (1883-1950) -, até meados do século XX pouco se avançou, em tal domínio. Além de uma certa predominância da "história económica estatística", já referida, os movimentos sociais, com destaque para o movimento operário, estavam então na ordem do dia. Acerca do assunto já se escreveu:

«Até aos anos 1970, as elites dos negócios têm despertado reduzida atenção aos historiadores». Jean Bouvier alertava para «o desequilíbrio existente entre o nosso conhecimento da classe trabalhadora e o da classe média, em particular do patronato, e o prejuízo que isso pode causar para a interpretação do passado» ${ }^{13}$. Como é sabido, a investigação histórica era então profundamente marcada por um certo tipo de ideologia, segundo a qual se deveria preferir aprofundar o conhecimento histórico dos "explorados", em detrimento do dos "exploradores".

${ }^{12}$ Alfred D. Chandler, La mano visible. La revolución en la dirección de la empresa norteamericana (trad, do inglês), Madrid, Ministerio de Trabajo y Seguridad Social, 1988; Escala y diversificación. La dinámica del capitalismo industrial, ts. I e II, Prensas Universitarias de Zaragoza, 1996.

"13 «Youssef Cassis' key lecture at Helsinki EBHA conference: Business elites and business history», European Business History Association, Newsletter n. ${ }^{\circ} 16$ Janeiro de 2003, p. 35. 
Carlos Dávila L. de Guevara, na introdução à obra dedicada à Empresa e História na América Latina, salienta, a propósito: «Além de razões próprias do desenvolvimento da história [empresarial] como disciplina, também considerações políticas e ideológicas exerceram a sua influência. Por várias décadas houve tabus poderosos que impediram muitos historiadores de se aproximar para estudarem o empresariado, visto por alguns como seu "principal inimigo"; por outros, como os "vende pátrias", "burguesia concupiscente" e "parasitária". Para muitos, o empresariado sempre despertou - com razão - suspicácias. Estes preconceitos estiveram ligados a processos económicos, políticos, ideológicos e sociais, com que se debateu mais do que uma geração de académicos e intelectuais» ${ }^{14}$.

Numa primeira fase, a história empresarial constituía apenas um mero apêndice da história económica. Com efeito, «num dos primeiros artigos publicados na Business History, T. S. Ashton (1959) clamava que o assunto era um mero auxiliar do seu estudo fulcral, a história económica, fornecendo-lhe apenas uma visão geral "da operação das forças económicas a actuar em primeira mão"»"

Porém, a situação mudou radicalmente nas últimas três décadas. Multiplicaram-se os estudos, monográficos, uns, de síntese e globais, outros. Incrementou-se o diálogo - ou, pelo menos, diminuiu a desconfiança e o desinteresse mútuo -, entre historiadores e responsáveis pelas empresas. Em muitos casos, estes não só abrem e disponibilizam os respectivos arquivos como promovem, ainda, a elaboração e a publicação de obras, de índole histórica, sobre as próprias organizações que lideram. Fazem-no, frequentemente, por ocasião das comemorações de uma data de aniversário com alguma relevância (por exemplo: $50^{\circ}, 100^{\circ}$, $150^{\circ}$ ou $200^{\circ}$ aniversário da respectiva fundação).

Do ponto de vista académico, tem crescido consideravelmente o número de publicações especializadas sobre a temática, ao mesmo tempo que têm sido leccionadas disciplinas e seminários de história empresarial. Esta, em certas universidades - sobretudo em cursos de economia e de gestão -, conquistou já a sua autonomia, relativamente à história económica, ao mesmo tempo que adquiriu, também, "dignidade" suficiente para ser eleita como objecto de dissertações, a apresentar e discutir em provas académicas. Giulio Sapelli, na sua estimulante obra intitulada, precisamente, L 'impresa come soggetto storico (Milão, 1990), interroga:

${ }^{14}$ Carlos Dávila L. de Guevara (comp.), Empresa e história na América Latina. Um balanço historiográfico, Bogotá, TM Editores, 1996, p. XI.

${ }^{15}$ John F. Wilson, British business history, 1720-1994, Manchester University Press, 1995, p. 19-20. 
«Existirá uma perspectiva que possa fornecer um contributo decisivo para a renovação dos estudos de empresa como momento essencial de uma ciência da sociedade?». Após algumas considerações sobre a metodologia a seguir, para que à pergunta formulada possa ser dada uma resposta afirmativa, acrescenta:

«De tal orientação metodológica e dos estudos inspirados por essa metodologia não poderá inferir-se um conceito de empresa deterministicamente definido pelo mercado mas, ao invés, o resultante da interacção da subjectividade da gestão, dos vínculos e da criatividade tecnológica, segmentação do mercado e da concorrência. Uma empresa "real", sempre mais perceptível não como objecto de uma temporalidade e de uma espacialidade a ela exteriores, mas como sujeito histórico, que determina a sua forma e o seu ambiente» ${ }^{16}$.

Não é este o lugar mais adequado para efectuar um balanço da evolução da história empresarial, nas última três décadas. Além disso, já dispomos de algumas sínteses que nos podem ajudar nessa tarefa. Entre outras, recordo a importante obra de John F. Wilson (British business history, 1720-1994, aliás já citada) e o interessantíssimo artigo de Geoffrey Jones, sob o título «Company History in the Business History in the 1990s $»^{17}$. Também, no que se refere a Portugal, eu próprio já fiz um primeiro esboço de balanço da referida evolução ${ }^{18}$.

Contudo, permito-me destacar algumas das tendências mais relevantes que têm vindo a verificar-se, na fileira da história das empresas e dos empresários.

A história empresarial tem permitido esclarecer diversos aspectos do âmbito da microeconomia, nomeadamente pelo contributo que tem dado ao estudo de questões-base como as seguintes: o que se produz? como se produz? como distribuir o produto ? $^{19}$

Ao invés do que se verificava nos alvores da história empresarial, têm vindo a diversificar-se os objectivos que presidem à elaboração de histórias de empresas. Assim, se em alguns casos se pretende homenagear os fundadores ou dar maior visibilidade ao negócio, pela comemoração pública de uma efeméride, noutros deseja conhecer-se mais profundamente o passado da empresa, não só pelo interesse que a respectiva história apresenta, em si mesma, como ainda para que, a partir de um melhor conhecimento da realidade, se tomem opções estraté-

${ }^{16}$ Giulio Sapelli, L'impresa come soggetto storico, Milão, Arnold Mondatori/Sggiatore, 1990, p. 17.

Wilfried Feldenkirchen and Terry Gourvish (eds.), European Yarbook of Business History, vol. 2, Inglaterra, ASHGATE on behalf of the Society for European Business History, 1999, p. 1 -20 (Manifesto o meu agradecimento ao Autor, por me ter fornecido cópia do artigo referenciado).

${ }^{18}$ José Amado Mendes, «A "velha" e a "nova" história empresarial em Portugal, 1924-1994. Tendências e resultados», Gestão e Desenvolvimento, 8, 1999, p. 97-113.

${ }^{19}$ C. M. Cipolla, op. cit., p. 6-7. 
gicas mais fundamentadas e adequadas à respectiva cultura organizacional. Nesse sentido, a história da empresa pode constituir um instrumento estratégico da maior utilidade para a "performance" económica geral ${ }^{20}$. Por outro lado, se o estudo da actuação dos empresários nos dá informação acerca da estratégia, o dos gestores elucida-nos sobre a táctica ${ }^{21}$.

No caso da Grã-Bretanha, onde a história empresarial tem já uma longa tradição, os historiadores têm sido influenciados por três modelos: a biografia institucional ou individual; o estudo comparado das estruturas e políticas empresariais; a análise do empresariado e o seu contributo ${ }^{22}$.

O caso inglês integra-se no chamado modelo anglo-saxónico e, especialmente, norte-americano de história empresarial, de acordo com o qual tem vindo a privilegiar-se o estudo das seguintes temáticas: o desenvolvimento organizativo, o crescimento tecnológico; e a dimensão dos mercados. Em contrapartida, segundo o modelo francês, como centro da análise encontram-se os paradigmas culturais da acção directiva e dos proprietários, cimentando uma fértil trajectória, analítica e prosopográfica ${ }^{23}$.

Dadas as semelhanças entre os modelos de industrialização português e francês, este afigura-se mais susceptível de ser aplicado à história empresarial portuguesa do que o anglo-saxónico. Além disso, como nota G. Jones no artigo citado, a cultura empresarial foi, precisamente, uma área negligenciada por Chandler e que necessita de ser estudada mais desenvolvidamente ${ }^{24}$. $\mathrm{O}$ assunto deverá ainda merecer uma atenção redobrada, se admitirmos, como já foi defendido, a existência de uma "arte de gestão europeia"2s.

Em virtude das múltiplas orientações que a história empresarial tem seguido, não surpreende que, para tal, tenham contribuído intenções e protagonistas diversos. De qualquer modo, tem-se verificado uma participação crescente, neste ramo historiográfico, de investigadores profissionais, inclusive académicos. Em muitos casos, os direitos e os deveres da empresa patrocinadora e do investigador, encarregado da elaboração da obra, ficam salvaguardados através de contrato escrito, celebrado especificamente para o efeito. Assim, procura

${ }^{20}$ J. F. Wilson, op. cit., p. 2.

Idem, p. 21.

${ }^{22}$ Idem, p. 2.

${ }_{23}$ Francisco Comím e Pablo Martín Aceña (coords.), La empresa en la Historia de España, Madrid, Ed. Civitas, 1996, p. 474-475.

${ }^{24}$ G. Jones, op. cit., p. 4.

Helen Bloom et. al., L'art du management européen (trad. do inglês), Paris, Les Éditions d'Organisation, 1994. 
contrariar-se o que é admitido por alguns, segundo os quais "patrocínio é sinónimo de controle" 26 .

Obviamente que nem todas as histórias de empresa são da autoria de historiadores com formação adequada e tendo a investigação histórica como actividade principal. Por vezes, ainda se entregam tais trabalhos a amadores ou a outros tipos de profissionais. Todavia, também aqui se têm registado algumas alterações. Enquanto até aos anos 1960, inclusive - por exemplo, no que concerne à história bancária, em Portugal - se solicitava, frequentemente, a um funcionário da organização que elaborasse a respectiva história (cujo nome, por vezes, era omitido ou colocado em local da obra pouco visível, inclusive no final), mais próximo da actualidade tem-se recorrido mais frequentemente a escritores, jornalistas, artistas, publicitários ou profissionais da área do "marketing", susceptíveis de dar da empresa uma imagem essencialmente favorável, sem grandes preocupações com o rigor e a metodologia históricas. Vejamos, por fim, como é que a história empresarial se poderá articular com a história económica e social.

\section{A História das Empresas como Mais-Valia para a História Económica e Social}

Com a perspectiva chandleriana da "mão visível" - por oposição à conhecida "mão invisível" de Adam Smith -, adquiriu maior relevância o estudo das formas de gestão. Daí o uso de expressões como "capitalismo de gestão", "capitalismo pessoal", "capitalismo familiar", etc.

Ora o estudo da administração e gestão das organizações não pode ser levado a cabo sem o contributo da história das empresas, alicerçada e fundamentada na investigação efectuada nos respectivos arquivos. Efectivamente, ao contrário da perspectiva tradicional, a evolução da economia e das próprias empresas não pode ser explicada deterministicamente pelas leis do mercado. Há que equacionar a questão considerando o papel fundamental desempenhado, entre outros, pelos seguintes agentes ou factores: políticas, ambiente cultural, tomadas de decisão pelos empresários e gestores; inovação (no sentido amplo que Schumpeter lhe atribuiu $^{27}$ ) e actualização tecnológica; recursos materiais e investimento em capital humano; mercado e concorrência; escala e organização empresarial. A propósito, atente-se nas seguintes palavras:

${ }^{26}$ Ver, sobre o assunto, Christopher J. Castaneda, «Writing contract business history», The Public Historian. A Journal of Public History, vol. 21, Winter 1999, n. ${ }^{\circ}$ 1, p. 11-29.

${ }^{27}$ Santiago López García y Jesús M. 'Valdaliso (eds.). Que inventen ellos? Tecnlogía, empresa y cambio económico en la España contemporánea, Madrid, Alianza Editorial, 1997, p. 59-60. 
«Como um "estudo de caso" [a história de uma empresa] proporciona uma janela através da qual nós podemos ver o passado, um ponto de vista que pode dar significado pessoal a eventos mais vastos. Mas o ponto de vista é limitado em escala, afectando, por um lado, a característica do trabalho e, por outro, a sua utilidade. Como alternativa, poderá considerar-se o indivíduo (ou a empresa) como um actor, como um mecanismo por meio do qual o leitor pode visitar eventos históricos mais amplos» ${ }^{28}$.

A nível mais alargado, também a história do capitalismo, nas últimas duas centúrias e meia, e das três revoluções industriais - como eventos fulcrais do respectivo processo - tem tudo a ganhar se for perspectivada à luz dos mais recentes desenvolvimentos da história empresarial. Como exemplo das vantagens que poderão advir dessa integração, recordo a excelente obra intitulada Creating Modern Capitalism. How entrepreneurs, companies, and countries triumphed in three Industrial Revolutions, coordenada por Thomas K. McCraw (Harvard University Press, 2000).

A medida que se estuda a evolução do capitalismo e o desenvolvimento das três revoluções industriais (que, simplificando, podemos identificar com o vapor, a electricidade e as novas tecnologias da informação), bem como os diversos modelos de que se revestiram, vai-se acompanhando a história de algumas das empresas consideradas mais emblemáticas, em cada um dos processos.

Entre outros exemplos, é interessante constatar como, a montante do conhecido fabricante japonês de automóveis "Toyota", se encontra uma empresa, também famosa, que produziu teares para a indústria têxtil, aliás com designação similar, isto é, "Toyoda"29. Acrescente-se que, também em Portugal, se detectam exemplos similares. Assim sucede, entre outros, com o caso da Nova Reguladora de Vila Nova de Famalicão - a nossa mais famosa produtora de relógios de sala, ao longo de cerca de um século -, cujo património histórico, tradição e cultura técnica e empresarial foram recentemente incorporados pela unidade da multinacional Schlumberger que, no mesmo local, fabrica actualmente aparelhos de medida e de controle, sofisticados e de elevada qualidade ${ }^{30}$.

A própria história social muito poderá beneficiar com o contributo da história das empresas. Como já foi sublinhado por François Caron, «a empresa deve ser considerada como o principal laboratório de mudança social» ${ }^{31}$. Este mesmo

${ }^{28}$ The Public Historian. A Journal of Public Histoty, vol. 23, Summer 2001, n. ${ }^{\circ}$ 3, p. 97.

${ }^{29}$ Op. cit., cap. 11, p. 396-438 : «Toyoda Automatic Looms and Toyoda Automobiles».

${ }^{30}$ José Amado Mendes e Isabel Fernandes (coords.), Património Industrial no Vale do Ave. Um passado com futuro, Vila Nova de Famalicão, ADRAVE, 2002, p. 33.

${ }^{3}$ Prefácio à obra coordenada por Maurice Hamon e Félix Torres, Memoire d'avenir. L'histoire dans l'entreprise. Paris, Economica, 1987, p. 9. 
autor, reputado historiador francês, após afirmar que a História tem tanta necessidade da empresa como a empresa da história, acrescenta:

«Pretender escrever a história de uma nação, num dado período, sem colocar no seu centro a das empresas é uma obra de mutilação voluntária, uma caricatura de história». Para justificar a asserção, Caron chama a atenção para os seguintes três tipos de evidência:

«1) A história económica geral, fundada sobre as perspectivas macroeconómicas, é incapaz de resolver, utilizando os instrumentos de análise de que dispõe, os problemas que suscita [...]. Às rupturas e às etapas artificialmente definidas pelos historiadores macroeconómicos é necessário opor, tanto os processos reais de continuidade constatados na vida dos negócios e na indústria como a extrema fragilidade e o carácter efémero, apesar das aparências, da instituição empresarial».

«2) A história dos sistemas e das hierarquias sociais não pode escrever-se sem ter em conta a evolução concreta dos "mercados internos do trabalho", na sua infinita diversidade. A uniformização dos sistemas sociais sob a pressão dos sindicatos é recente e não faz desaparecer a infinita diversidade dos comportamentos e dos princípios organizacionais».

«3) Finalmente, a história cultural e a história política da nação têm uma e outra necessidade de integrar as realidades infinitamente variadas da empresa. É no seu seio que se elaboram os comportamentos sociais novos e as novas culturas, tanto ou mais que nas organizações associativas e políticas». E conclui o autor: «Assim, nenhum dos aspectos da história geral pode ignorar a realidade da empresa. Ao invés, é claro que a empresa não pode continuar a ignorar a sua própria história» ${ }^{32}$.

\section{Conclusão}

Do que, sucintamente, se acaba de expor poderá inferir-se que começa a verificar-se uma certa consciencialização, acerca da necessidade de incorporar os resultados da investigação histórica mais recente nos estudos a empreender sobre as diversas temáticas. No que à história económica e social diz respeito, há que torná-la mais humana, mais concreta e menos dependente de teorias que, por vezes, levam não a procurar esclarecer as questões, mas sim a tentar encontrar-se justificação e comprovação para modelos previamente definidos. Sob estas perspectivas, a história empresarial poderá prestar uma excelente ajuda.

Evidentemente que também esta necessita de actualização e aperfeiçoamento, procurando noutras áreas - com destaque para a história económica e 
social - contributos que lhe possam ser úteis. Assim, a história de empresas, apologética e laudatória, destinada a glorificar organizações e/ou os seus líderes, encontra-se ultrapassada. Por isso, deve ser substituída por outra, onde o rigor, a objectividade (na medida do possível, no âmbito das ciências humanas e sociais), o estudo aprofundado da realidade - com base em testemunhos significativos e fidedignos - e o espirito crítico deverão ser uma constante.

Certos autores, que se têm debruçado sobre a questão, fornecem-nos algumas sugestões, das quais me permito destacar as duas que se seguem. José Luis Garcia Ruiz, na obra Historia económica de la empresa moderna (Madrid, 1994), sublinha:

«Partindo do conhecimento da história económica das organizações empresariais, trata-se de procurar encontrar uma explicação teórica e formal [para as instituições económicas do capitalismo, a partir dos custos de transacção], cujo enfoque pretende: 1) ser microanalítico; 2) estar consciente das assunções que se fazem sobre a conduta humana; 3 ) desenvolver a importância dos activos que entram em jogo; 4) atribuir grande importância à análise comparativa; 5) contemplar a empresa como uma "estrutura de governo" mais do que como uma "função da produção"; e 6) deter-se nas dificuldades dos contratos que marcam a actividade empresarial $»^{33}$.

Por sua vez, Giulio Sapelli propõe um novo modelo teórico para aquela a que chama uma nova história de empresa. No seu elucidativo e estimulante trabalho, o especialista italiano começa por afirmar: «A história da empresa é uma disciplina académica consolidada. Em quase todo o mundo existem agora cátedras universitárias e institutos de investigação. Ensinam-se e praticam-se conceitos e metodologias dirigidas a reconstruir o conhecimento e o desenvolvimento daquela que é hoje, com os Estados nacionais e as organizações internacionais, uma das mais poderosas realidades associativas da história contemporânea $»^{34}$.

$\mathrm{Na}$ impossibilidade de analisar aqui, em pormenor, toda a riqueza metodológica e conceptual do trabalho citado, apenas gostaria de recordar dois aspectos que considero da maior relevância: a) a centralidade que o autor atribui à dimensão cultural, no âmbito da história das empresas; b) a necessidade de «focar os problemas da história da empresa do ponto de vista das ciências sociais e de se entender esta disciplina como parte de uma nova e mais geral compreensão da sociedade ${ }^{35}$

3 José Luis Garcia Ruiz, Historia económica de la empresa moderna. Madrid, Ed. Istmo, 19994, p. 17.

${ }^{34}$ Giulio Sapelli, «La construcción social e historia de la empresa: para un nuevo modelo teorico», F. Comin e P. Martín Aceña, La empresa en la historia de España, p. 473-487 (itálico meu). ss Idem. p. 476-477. 
Bibliografia

ALLEN, Robert Loring, Joseph Schumpeter. Su vida y su obra (trad, do inglês), Valência, Ed. Alfons Magnànim, 1995.

ATSMA, Hartmut e BURGUIÈRE (coord.), Marc Bloch aujourd'hui. Histoire comparée \& sciences sociales, Paris, Ed. de EHESS, 1990.

BLOOM, Helen et al., L'art du management européen, Paris, Les Éditions d'Organisation, 1994.

CASTANEDA, Christopher J., «Writing contract business history», The Public historian. A Journal of Public History, vol. 21, Winter 1999, n. ${ }^{\circ}$ 1, p. 11 -29.

CHANDLER, Alfred D., La mano visible. La revolución en la dirección de la empresa norteamericana (trad. do inglês), Madrid, Ministerio de Trabajo y Seguridad Social, 1988.

CHANDLER, Alfred D., Escalay diversificación. La dinámica del capitalismo industria (trad. do inglês), ts. I e II, Prensas Universitarias de Zaragoza, 1996. CIPOLlA, Carlo M., Between history and economics. An Introduction to economic history (trad. do italiano), Inglaterrra, Basil Blackwel, 1991.

COMín, Francisco (coords.), La empresa en la historia de Espana, Madrid, Ed. Civitas, 1996.

ETEMAD, Bouda et al. (coords.), Pour une histoire économique et sociale inter national. Mélanges offerts à Paul Bairoch, Genève, Ed. Passé Présent, 1995.

GARCIA RUIZ, José, Historia económica de la empresa moderna, Madrid, Ed. Istmo, 1994.

GODINHO, Vitorino Magalhães, Introdução à história económica, Lisboa, Livros Horizonte, s. d.

GUEVARA, Carlos Dávila L. de (comp.), Empresa e história en América Latina. Un balance historiográfico, Bogotá, TM Editores, 1996.

HAMON, Maurice e TORRES, Félix (coords.), Mémoire d'avenir. L'histoire dans l'entreprise, Paris, Economica, 1987.

JONES, Geoffrey, «Company history and business history in the 1990s », Wilfried Feldenkirchen and Terry Gourvich (cords.), European Yearbook of Business history, vol. 2, Inglaterra, ASHGATE on behalf of the Society for European business History, 1999, p. 1-20.

KHUN, Thomas S., La structure des révolutuions scientifiques (trad. do inglês), Paris, Flammarion, 1972.

LÓPEZ GARCÍA, Santiago y Jesús M. ${ }^{a}$ Valdaliso (eds.), Que inventen ellos? Tecnología, empresa y cambio económico en la Espana contemporánea, Madrid, Alianza Universidad, 1997. 
MARICHAL, Carlos e CERUTTI, Mario (comp.), Historia de las grandes empresas en México, 1850-1930, México, Universidad autónoma de Nuevo Léon/Fondo de Cultura Económica, 1997.

McCRAW, Thomas K., Creating modem capitalism. How entrepreneurs, companies and countries triumphed in three Industrial Revolutions, 3. reimp., Harvard University Press, 2000.

MENDELS, F., «Histoire économque», BURGUIÈRE, André, Dictionnaire des Sciences Historiques, Paris, PUF, 1986, p. 215-223.

MENDES, José Amado, «A «velha » e a «nova » história empresarial em Portugal, 1924-1994. Tendências e resultados», Gestão e Desenvolvimento, 8, 1999, p. 97-113.

MENDES, José Amado e FERNANDES, Isabel (coords.), Património Industrial no Vale do ave. Um passado com futuro, Vila Nova de Famalicão, ADRAVE, 2000.

Public Historian (The). A Journal of Public History, vol. 23, Summer 2001, n. ${ }^{\circ} 3$. SAPELLI, Giulio, L 'impresa come soggetto storico, Milão, Saggiatore, 1990. WILSON, John F, British business history, 1720-1994, Manchester University Press, 1995.

«Youssef Cassis' key lecture at Helsinki EBHA conference: Business elites and business history», European Business History Association, Newsletter $n .^{\circ} 16$, January 2003, p. 35-45. 